\title{
Influence of UVB-Irradiation on the Structures and Solid Particle Erosion Resistance for CF/PC Composites
}

\author{
Mei Fang1, Yuji Ma1, Na Zhang1* ${ }^{*}$, Ming Huang1,2, Jose Castro ${ }^{3}$, Xianhu Liu ${ }^{1}$, \\ Chuntai Liu', Changyu Shen ${ }^{1}$
}

${ }^{1}$ National Engineering Research Center for Advanced Polymer Processing Technology, Zhengzhou University, Zhengzhou, China ${ }^{2}$ State Key Laboratory of Structural Analysis for Industrial Equipment, Dalian University of Technology, Dalian, China ${ }^{3}$ Department of Integrated Systems Engineering, The Ohio State University, Columbus, USA

Email: *nazhang@zzu.ed.cn, shency@zzu.edu.cn

How to cite this paper: Fang, M., Ma, Y.J., Zhang, N., Huang, M., Castro, J., Liu, X.H., Liu, C.T. and Shen, C.Y. (2020) Influence of UVB-Irradiation on the Structures and Solid Particle Erosion Resistance for CF/PC Composites. Journal of Materials Science and Chemical Engineering, 8, 1-7. https://doi.org/10.4236/msce.2020.86001

Received: May 20, 2020

Accepted: June 25, 2020

Published: June 28, 2020

Copyright $\odot 2020$ by author(s) and Scientific Research Publishing Inc. This work is licensed under the Creative Commons Attribution International License (CC BY 4.0).

http://creativecommons.org/licenses/by/4.0/

\begin{abstract}
The service life and properties of Carbon fiber reinforced polycarbonate (CF/PC) composites are seriously affected by ultraviolet radiation from outdoor exposure during aging. In this work, the changes of structure and solid particle erosion resistance for $\mathrm{CF} / \mathrm{PC}$ composites after ultraviolet irradiation were studied. It was shown that ultraviolet irradiation causes photo-oxygen aging and photo-fries re-arrangement of the composite, and the result was confirmed by FTIR. We correlated the solid particle erosion resistance with aging time, and found that the solid particle erosion resistance of $\mathrm{CF} / \mathrm{PC}$ composites greatly decreased by UVB irradiation during 15 hours. Furthermore, the eroded material surface was analyzed using scanning electron microscope (SEM). It suggests that ultraviolet aging leads to plasticization and degradation, resulting in reduction of erosion resistance of the composite.
\end{abstract}

\section{Keywords}

Polymeric Composites, Sand Erosion, UVB Irradiation, FTIR

\section{Introduction}

Polycarbonate (PC) is a ductile polymer with excellent physical and chemical properties, such as good thermodynamic stability, high strength and high temperature resistance [1]. However, the aging of PC products is inevitable in the process of service due to temperature, light, heat and other environmental factors [2]. Among them, ultraviolet aging plays a major role. 
Ultraviolet aging of polycarbonate has been extensively studied. It has been reported that PC exposure to ultraviolet radiation induces a series of complex chemical reactions, which leads to degradation of the material and fracture of molecular chains [3] [4] [5]. Rivaton et al. [6] found that chemical bonds in PC chains (C-C, C-O, and C-H, etc.) are easily excited and destroyed by ultraviolet light. Diepens et al. [7] [8] [9] [10] [11] consider that photo-fries rearrangement reaction takes place in polycarbonate with ultraviolet of wavelength less than 300 $\mathrm{nm}$, while photo-oxidation aging mainly occurs when the ultraviolet wavelength is larger than $300 \mathrm{~nm}$.

In order to improve the ultraviolet aging resistance of PC products, carbon fiber (CF) with good chemical stability was used in this work. The aging process of CF/PC composites by ultraviolet $\mathrm{B}$ rays (UVB) was investigated. The variation of functional groups after UVB was measured by FTIR. The effects of UVB on solid particle erosion for $\mathrm{CF} / \mathrm{PC}$ composites were evaluated in this work.

\section{Experimental Section}

\subsection{Materials}

Makrolon series PC from Covestro was used. T700SC-3K Carbon fiber (CF) supplied was also provided by Covestro with a density of $1.5 \mathrm{~g} / \mathrm{cm}^{3}$. Unidirectional tapes were laid at different directions $\left(0^{\circ} / 90^{\circ} /+45^{\circ} /-45^{\circ} /-45^{\circ} /+45^{\circ} / 90^{\circ} / 0^{\circ}\right)$ to manufacture a prepreg laminate. The prepreg with a thickness of $2 \mathrm{~mm}$ has a CF content of $60 \mathrm{wt} \%$. The ultraviolet aging was conducted in a spray (ZN-P model) UV aging box (Shanghai Linpin Company). Samples were exposed to medium wave ultraviolet (UVB) light for different times $(0,15,30,45,60 \mathrm{~h})$ at $60^{\circ} \mathrm{C}$.

\subsection{Characterizations}

The change of internal microstructure of the CF/PC composites during UVB aging was characterized by FTIR (Nicolet 6700, USA) instrument. The data were collected in a range from 650 to 4000 wave numbers. The resolution was $4 \mathrm{~cm}^{-1}$. Each sample was scanned for 64 times. The variation of sand erosion resistance for the $\mathrm{CF} / \mathrm{PC}$ composites with different aging times was conducted at room temperature $\left(25^{\circ} \mathrm{C}\right)$ using a gas jet equipment (STR-9060). Specimens were cut into strips of $35 \times 12 \mathrm{~mm}^{2}$ in dimension and fixed on a steel plate. During the experiment solid particles were driven by flowing air (0.34 MPa) from a $\mathrm{B}_{4} \mathrm{C}$ nozzle and impacted on surface of the samples. The particles used were silicon carbide $(\mathrm{SiC})$ with average diameter of between $300-800 \mu \mathrm{m}$. The distance between the samples and the nozzle was $30 \mathrm{~mm}$. Each sample was eroded at $30^{\circ}$. The weight loss was measured and calculated from the formula:

$$
\Delta M=M_{0}-M_{t} .
$$

where $M_{0}$ is the initial sample weight, $M_{t}$ is the weight after erosion. The results were averaged by seven groups of data. The eroded surfaces of CF/PC composites before and after UVB irradiation were characterized by JSM-7500F scanning electron microscope (SEM). 


\section{Results and discussion}

Possible chemical reaction of $\mathrm{CF} / \mathrm{PC}$ composites under UVB irradiationis was shown schematically in Figure 1. Based on the research results of Diepens et al. [11] and our infrared test analysis, we found that both photo-fries and photo-oxygen aging occur for CF/PC composites when exposure to UVB irradiation.

PC absorbed photons to produce free radicals. Further, methyl salicylate and 2,2'-dihydroxybenzophenoneresulted are products of free radicals rearranging and recombining. Photo-oxygen aging occurs when $\mathrm{CF} / \mathrm{PC}$ composites are subjected to UVB under aerobic conditions. The dimethy groups between two benzene rings in PC chain were oxidized to form free radicals. Finally, ketones, phenols and carboxylic acids were formed through a series of complex reactions [12] [13].

In order to verify the aging mechanism of composites under ultraviolet light, $\mathrm{CF} / \mathrm{PC}$ composites were tested and analyzed by FTIR. The results are displayed in Figure 2. A small absorption peak can be observed at $1597 \mathrm{~cm}^{-1}$ (from Figure 2(a)) after irradiation, and the intensity of the absorption peak increases as the irradiation time increase. However, there was no absorption peak at this position of unaged samples. By referring to Figure 1, we can say that the absorption at $1597 \mathrm{~cm}^{-1}$ was caused by the free vibration of the carbonyl group in 2,2'-dihydroxybenzophenone. This indicates that the Photo-fries rearrangement occurs in CF/PC composites under UVB irradiation.

The absorption peak of irradiated samples increases significantly compared to that unaged at $1770 \mathrm{~cm}^{-1}$, indicating the formation of carboxylic acid groups. At the same time, the sample has a prominent peak at $1400-1360 \mathrm{~cm}^{-1}$ after ultraviolet aging, which is caused by the absorption vibration of hydroxyl groups (see Figure 2(b)). The production of carboxyl group proves that the photo-oxygen aging reaction occurred under the action of ultraviolet radiation. Both photo-fries rearrangement and photo-oxygen aging produce hydroxyl groups.

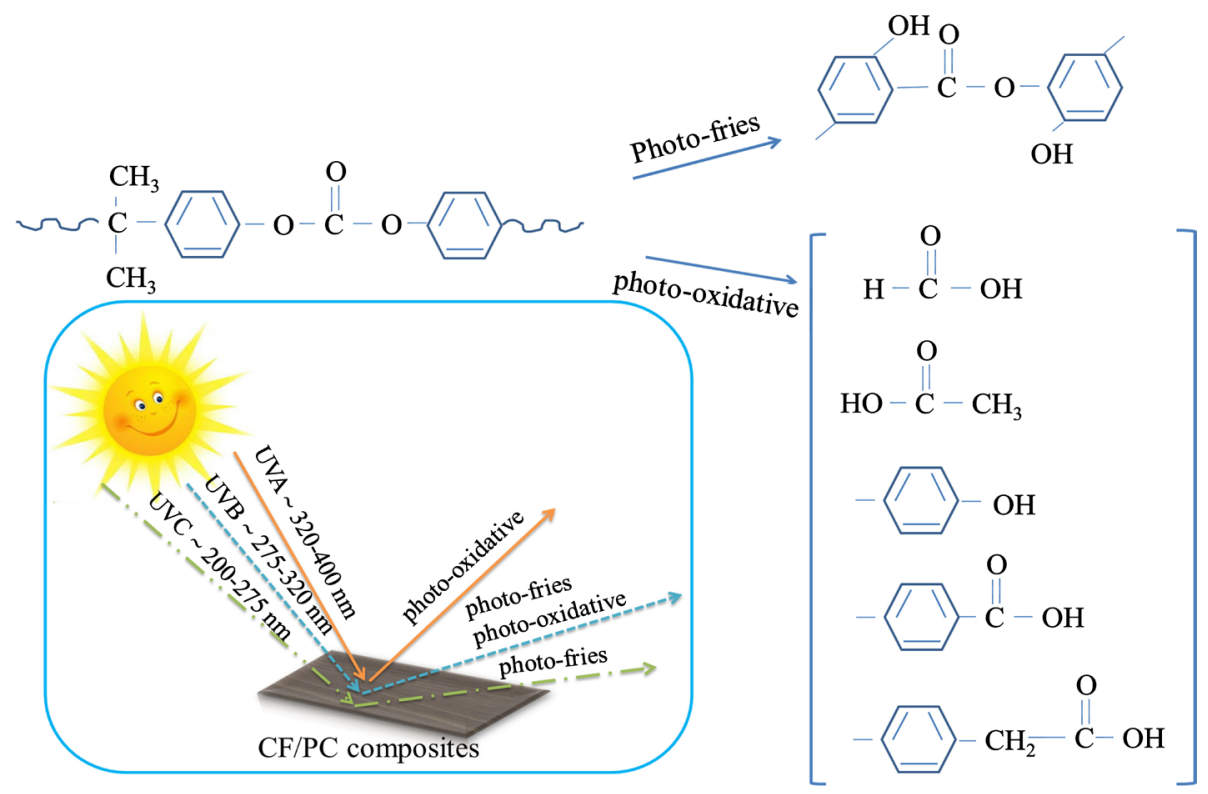

Figure 1. Reaction of polycarbonate under ultraviolet irradiation. 


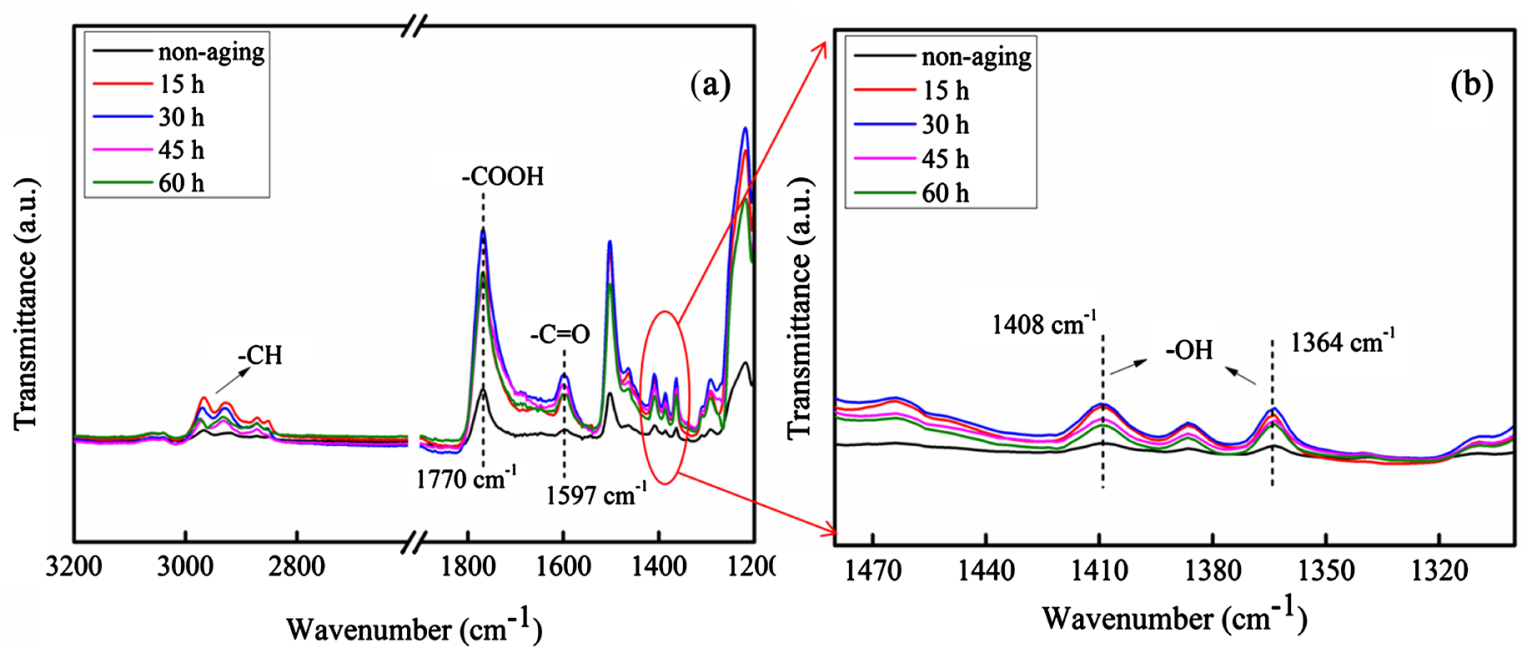

Figure 2. FTIR spectra of CF/PC composites for different aging time.

Besides, the absorption peaks of aliphatic $\mathrm{C}-\mathrm{H}$ bonds are in the range of 3000 $2800 \mathrm{~cm}^{-1}$ and $3100-3000 \mathrm{~cm}^{-1}$. This provides further evidence of the photo-oxygen reaction. We can observe that $\mathrm{CF} / \mathrm{PC}$ composites have a slight increase of the infrared absorption peaks in the range of $3000-2800 \mathrm{~cm}^{-1}$ and $3100-$ $3000 \mathrm{~cm}^{-1}$ after aging. This indicates that the formation of aliphatic $\mathrm{C}-\mathrm{H}$ bonds increased after ultraviolet irradiation. Indeed, Figure 2 fact agrees with Figure 1 theory perfectly.

The rigid groups of phenols and ketonesmay increase the surface hardness of materials [13]. Meanwhile, the recombination of free radicals prompts more density molecular chain. Therefore, the macroscopic properties of CF/PC composites (such as the surface hardness and solid particle erosion resistance) were affected by UVB ultraviolet irradiation.

The erosion rate of $\mathrm{CF} / \mathrm{PC}$ composites as a function of aging time is shown in Figure 3. The erosion rate of $\mathrm{CF} / \mathrm{PC}$ composites increases first and then decreases, which means that the solid particle erosion resistance of the material first decreases and then slightly increases. On the whole, UVB radiation results in the degradation of solid particle erosion resistance for $\mathrm{CF} / \mathrm{PC}$ composites. The solid particle erosion resistance of the samples aged for $15 \mathrm{~h}$ decreased by $13.9 \%$ compared with the unaged specimens. However, the erosion resistance of CF/PC composites improved after 15 hours, to about $8.2 \%$ lower than that of the unaged samples.

There are two causes of ultraviolet aging on the internal structure of materials. On one hand, the production of phenols/ketones that contain benzene rings enhanced the surface hardness of $\mathrm{CF} / \mathrm{PC}$ after photo-oxidative aging. The solid particles erosion resistance decreases with the increase of surface hardness. Therefore, the erosion resistance of samples aged for 15 hours was seriously reduced. On the other hand, as aging progresses, the crack grows in depth under sand erosion, some small particles embedded in the cracks and voids, giving the appearance of less material weight loss. 
The failure mode of $\mathrm{CF} / \mathrm{PC}$ composites includes matrix stripping, fiber fracture and material removal. Under $30^{\circ}$ erosion angle, the CF/PC composite is subjected to significant shear deformation. The eroded surfaces of CF/PC composites without aging are shown in Figure 4(a) \& Figure 4(b). From those two pictures, it is clear that only the matrix on the surface was damaged, and the wear of the fiber was very low, indicating that the PC matrix of unaged material has better erosion resistance. At the same time, it can be seen that the interface between fiber and matrix of unaged samples are well integrated.

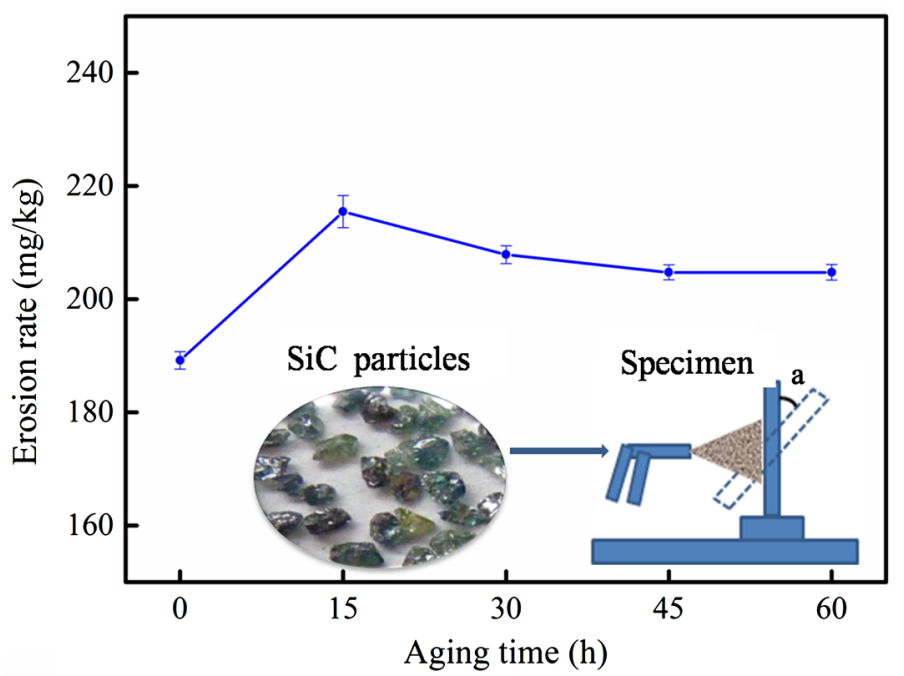

Figure 3. Sand erosion tests of $\mathrm{CF} / \mathrm{PC}$ composites, $30^{\circ}, 1 \mathrm{~min}, 50 \mathrm{psi}$.

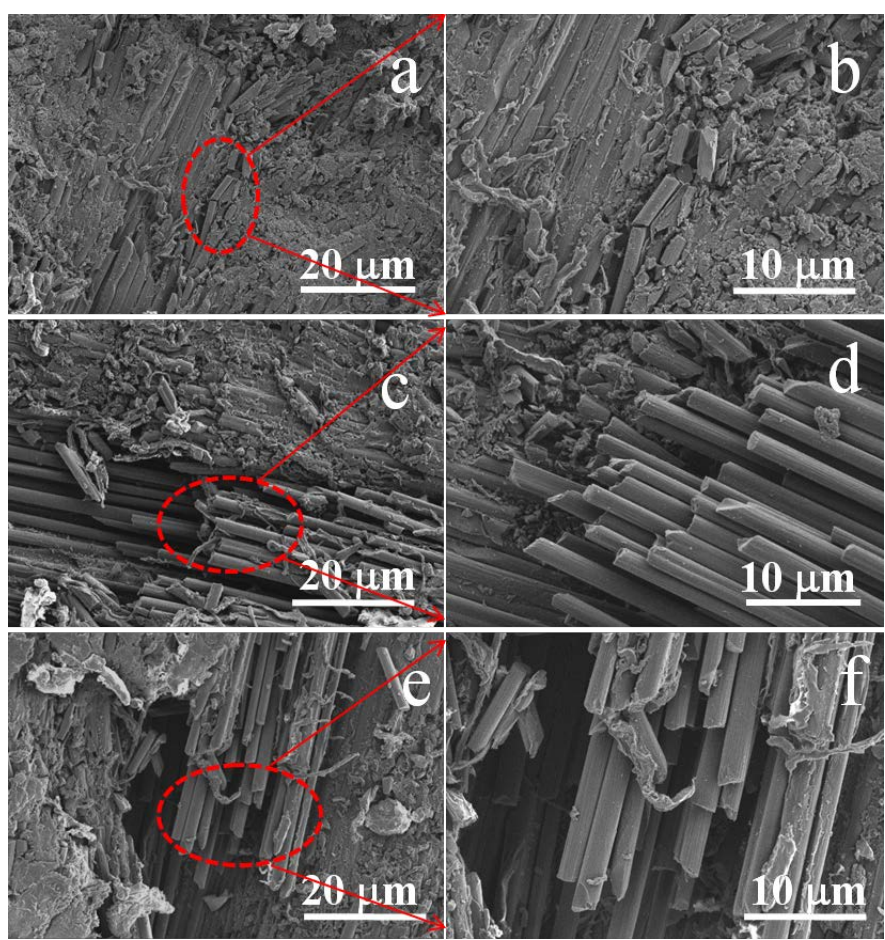

Figure 4. Surface morphologies of CF/PC composites: ((a), (b)): Unaged; ((c), (d)): Aging for $15 \mathrm{~h}$; ((e), (f)): Aging for $60 \mathrm{~h}$. 
After 15 and $60 \mathrm{~h}$ aging, a small amount of matrix was attached to the fiber surface (see Figures $4(\mathrm{c})-(\mathrm{f})$ ) compared with the unaged material (see Figure 4(a), Figure 4(b)). Figure 4(c) \& Figure 4(d) shows that matrix stripping and fiber fracture occurred on material under $15 \mathrm{~h}$ ultraviolet aging after sand erosion. The material is peeled off and a large number of fibers are exposed. Deep cracks and smooth fiber bundle can be clearly observed. Deep cracks and gullies can be seen on the surface of specimens after 60 hours of UVB aging (see from Figure 4(e), Figure 4(f)). Some small erosion particles, powder and micro debris buried in the crack, which are difficult to get out of the material. This is the reason that the solid particle erosion resistance of the $\mathrm{CF} / \mathrm{PC}$ composite in Figure 3 decreased first and then increased.

\section{Conclusion}

This work presents the effects of UVB irradiation on the structure and erosion resistance properties for $\mathrm{CF} / \mathrm{PC}$ composites. After UVB irradiation, both photo-fries rearrangement and photo-oxygenation occurred in $\mathrm{CF} / \mathrm{PC}$ composites. The plasticization and degradation of the material surface reduce its solid particle erosion resistance. The results of SEM further demonstrate the decrease of interface bonding for $\mathrm{CF} / \mathrm{PC}$ composites after ultraviolet aging.

\section{Acknowledgements}

This work was supported by the National Natural Science Foundation of China (11432003), 111 Project (D18023), Foundation of Henan (162300410246), and the Open Fund of State Key Laboratory of Structural Analysis for Industrial Equipment of DUT (GZ18203).

\section{Conflicts of Interest}

The authors declare no conflicts of interest regarding the publication of this paper.

\section{References}

[1] Messana, A., Airale, A.G., Ferraris, A., et al. (2017) Correlation between Thermo-Mechanical Properties and Chemical Composition of Aged Thermoplastic and Thermosetting Fiber Reinforced Plastic Materials. Materialwissenschaft und Werkstofftechnik, 48, 447-455. https://doi.org/10.1002/mawe.201700024

[2] Huang, J., He, C., Pan, G., et al. (2016) A Theoretical Research on Pyrolysis Reactions Mechanism of Coumarone-Contained Lignin Model Compound. Computational and Theoretical Chemistry, 1091, 92-98. https://doi.org/10.1016/j.comptc.2016.07.016

[3] Huang, J., He, C., Wu, L., et al. (2016) Thermal Degradation Reaction Mechanism of Xylose: A DFT Study. Chemical Physics Letters, 658, 114-124. https://doi.org/10.1016/j.cplett.2016.06.025.

[4] Huang, J., He, C., Li, X., et al. (2018) Theoretical Studies on Thermal Degradation Reaction Mechanism of Model Compound of Bisphenol A Polycarbonate. Waste Management, 71, 181-191. https://doi.org/10.1016/j.wasman.2017.10.016 
[5] Pickett, J.E. (2011) Influence of Photo-Fries Reaction Products on the Photodegradation of Bisphenol-A Polycarbonate. Polymer Degradation and Stability, 96, 2253-2265. https://doi.org/10.1016/j.polymdegradstab.2011.08.016

[6] Diepens, M. and Gijsman, P. (2008) Photo-Oxidative Degradation of Bisphenol A Polycarbonate and Its Possible Initiation Processes. Polymer Degradation and Stability, 93, 1383-1388. https://doi.org/10.1016/j.polymdegradstab.2008.03.028

[7] Geretovszky, Z., Hopp, B., Bertoti, I., et al. (2002) Photodegradation of Polycarbonate under Narrow Band Irradiation at $172 \mathrm{~nm}$. Applied Surface Science, 186, 85-90. https://doi.org/10.1016/S0169-4332(01)00615-8

[8] Migahed, M.D. and Zidan, H.M. (2006) Influence of UV-Irradiation on the Structure and Optical Properties of Polycarbonate Films. Current Applied Physics, 6, 91-96. https://doi.org/10.1016/j.cap.2004.12.009

[9] Rivaton, A., Sallet, D. and Lemaire, J. (1983) The Photochemistry of Bisphenol-A Polycarbonate Reconsidered. Polymer Photochemistry, 3, 463-481. https://doi.org/10.1016/0144-2880(83)90102-1

[10] Rivaton, A. (1995) Recent Advances in Bisphenol-A Polycarbonate Photodegradation. Polymer Degradation and Stability, 49, 163-179. https://doi.org/10.1016/0141-3910(95)00069-X

[11] Zweifel, H. (1999) Stabilization of Polymeric Materials. Annales de Chimie Science des Matériaux, 24, 401. https://doi.org/10.1016/S0151-9107(99)80080-4

[12] Diepens, M. and Gijsman, P. (2007) Photodegradation of Bisphenol A Polycarbonate. Polymer Degradation and Stability, 92, 397-406.

https://doi.org/10.1016/j.polymdegradstab.2006.12.003

[13] Claude, B., Gonon, L., Duchet, J., et al. (2004) Surface Cross-Linking of Polycarbonate under Irradiation at Long Wavelengths, Polymer Degradation and Stability, 83, 237-240. https://doi.org/10.1016/S0141-3910(03)00267-2 